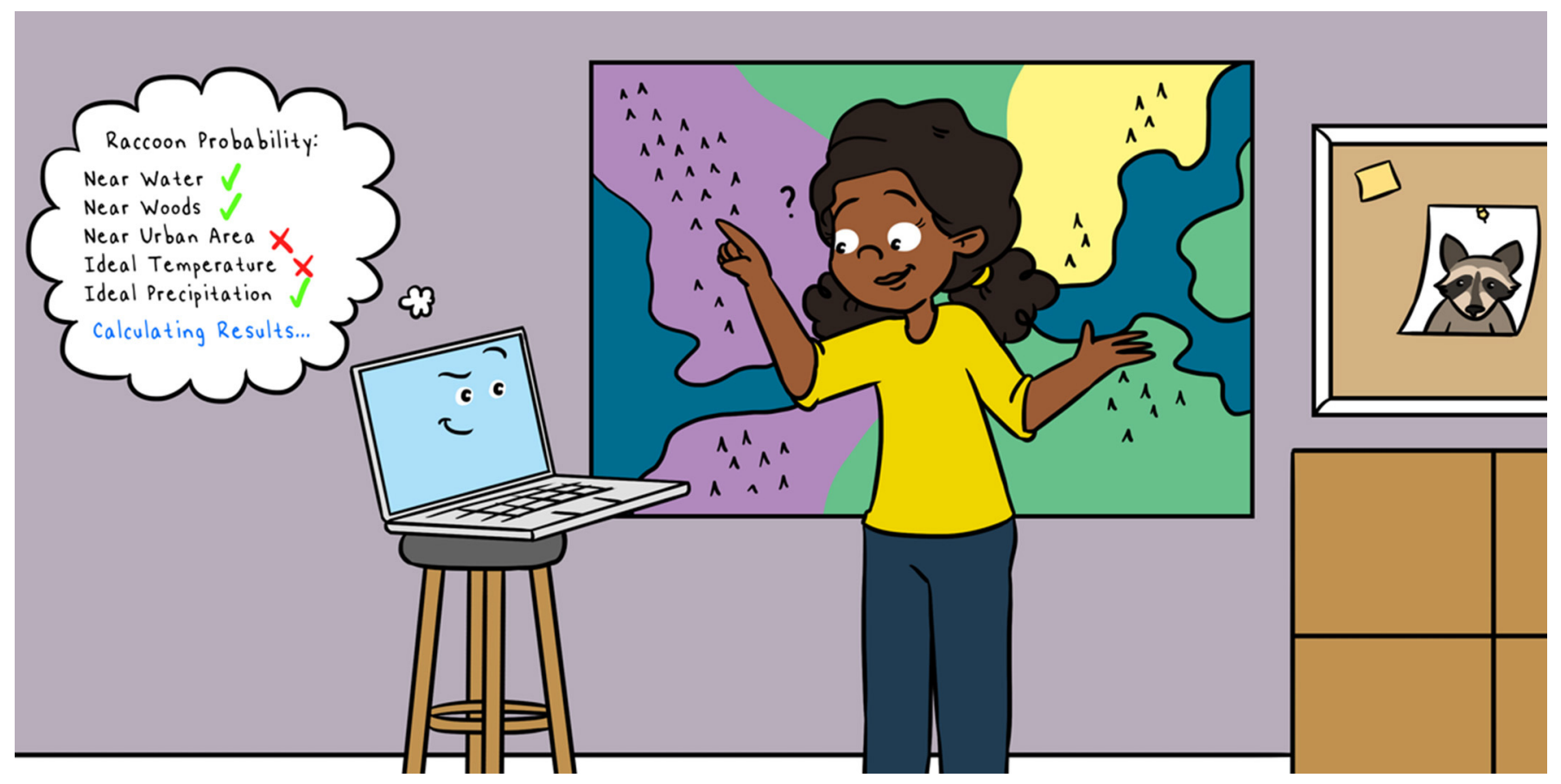

\title{
COMPUTERS CAN HELP US FIND RACCOONS AND OTHER LIVING CREATURES
}

\section{Gracielle Teixeira Higino *, Norma Forero, Francis Banville, Gabriel Dansereau and Timothée Poisot}

Quantitative \& Computational Ecology Laboratory, Département de Sciences Biologiques, Université de Montréal, Montréal, QC, Canada

YOUNG REVIEWERS:

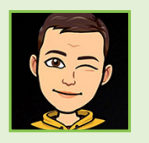

DARIO

AGE: 14

(E) LEONIE

AGE: 13

VALERIE

AGE: 13
If we want to protect our environment, we first need to know where animals and plants are. Are they hidden in the woods? Are they next to cities? Which woods or which cities? Wandering all over the world to find where living things are might seem exciting at first. However, in the long run, it might get a little tiring, no? Thankfully, we do not need to explore every corner of the Earth to know where the animals and plants are. Scientists instead use computers to deduce where certain species might be. In this article, we will describe how to find where raccoons live, by giving a computer special instructions. To do so, we just need a few observations of raccoons, the environmental conditions in which they have been identified, and a set of instructions to give to our computer.

\section{FINDING PLANTS AND ANIMALS}

Have you ever noticed how, when you travel to a place far away, you stop seeing the kinds of animals you usually see back home? Or that 


\section{ECOLOGIST}

Scientist who studies species and their interaction with the environment.

\section{OMNIVOROUS}

Able to eat both plants and other animals.

\section{DATA}

Organized information that can be used to answer specific questions. when a biologist on TV goes to a place that is really far from where you live, she shows a lot of birds, mammals, and plants you have never seen before? How do we know where we can find those animals and plants?

We could try to explore every corner of the Earth and list all the living creatures that are present in each spot. Scientists used to understand nature by doing observations like that, and it was a tremendous amount of work to go all around the world sampling everything. Today, we still want to know where all the living creatures are, but present-day ecologists can use computers to answer these questions without having to leave their labs, and you can help them do that too!

\section{THE CASE OF RACCOONS}

Imagine you want to know how far you need to go from your home to find a raccoon. You first need to know a little bit about raccoons, like where they live and what they like to eat. So, you look them up and find some information.

The raccoon mating season happens around January and lasts $\sim 2$ months, after which the female gives birth to 4-6 cubs. Thus, when you see groups of raccoons, it is surely a family taking a walk. At 10 months old, the baby raccoons will become independent and will hunt their own food and choose a new place to live. But how do raccoons choose their dens?

Biologists discovered that raccoons usually select a wooded area near a water source, but any quiet place with food and water can be a den. And what about dinner? Raccoons' front legs are very sensitive, providing them with a useful tool to discover what is on the menu! These animals have an omnivorous diet, which means they eat plants, insects, frogs, eggs, and rodents such as rats. With such a varied diet, raccoons can take advantage of humans, because we are also omnivorous and we waste a lot of food. Thus, raccoons can easily feast on what we throw in the garbage every day!

All this data about raccoons tells us a lot about where we have the highest chance of finding them: in areas where there are trees, food (even garbage!), and water, and we can probably find more of them together at the beginning of the year. Computers come in handy to help us analyze all the data and find the raccoons, or any other species we are interested in [1].

\section{HOW COMPUTERS CAN HELP ECOLOGISTS}

When we ask a computer to help us find raccoons, we first share with the computer what we already know about those animals, so that 


\section{ALGORITHM}

A specific procedure for solving a well-defined computational problem. the computer understands what the environment should be like for raccoons to live there. Then we can show the computer a different environment, and it will tell us how likely it is that we will find raccoons there, based on that environment's characteristics. How does the computer actually do this?

To help us identify places where certain animals might live, a computer uses something called an algorithm, which is a sequence of orders the computer follows to reach an answer. We may not realize it, but we all make decisions each day in a way similar to that used by computers. For example, before we go outside, we must decide what we should wear. So, we gather some information, such as which clean clothes are available and whether it is raining or not. The next step is to exclude options based on this information, using a sequence of statements: if it is raining, we will wear a jacket and boots; if it is not raining, we will wear a t-shirt; if it is raining, but the jacket is not clean...well, we can either wear a dirty jacket or stay home!

Computers can apply the same logic to our raccoon problem: if an environment is too cold and snowy, or too hot and dry, raccoons will probably not be found there. If there is no food they can eat, they will probably not be there either. On the contrary, if there is a forest where the temperature is neither too cold nor too hot, and if there is enough clean water to drink, raccoons might be present, hidden somewhere in the woods. They might also be present if there is a city or a village nearby, with lots of food for them to eat at the "trash buffet."

After running the algorithm, the computer displays a bunch of numbers, called probabilities. These numbers describe the chance of something being true-in this case, that raccoons will be found in an environment. According to the information we provided the computer, it calculates a number, between 0 and 1, for every place in the world. If this number is low, you might not be able to find a raccoon there. However, if this number is high, a raccoon might be hiding there somewhere [2]. We can then use these numbers to make beautiful maps!

\section{WHERE MIGHT THE RACCOONS BE?}

We made one such map (Figure 1) using two types of information: the precise locations where raccoons have been observed in the past, along with details of these locations, including temperature, total precipitation, and the presence of trees, water, and urban places (meaning garbage)!

From this map, our computer learned about the characteristics of a suitable habitat for raccoons. Then we asked our computer to look at sites all over the whole world and to tell us the chances that we could find a raccoon in each place. The computer then attributed 
Figure 1

This map

shows locations where raccoons are known to live now. For each spot, we gathered information about the presence of raccoons, the location's temperature, total precipitation, and the presence of trees, water, and urban places. These details of the environments in which raccoons were found were used to create a computer algorithm that could predict other locations likely to have raccoons (as we see in Figure 2). Raccoon emoji designed by Freepik.

\section{PROBABILITY}

Numerical measure of the chance that a particular event will occur.

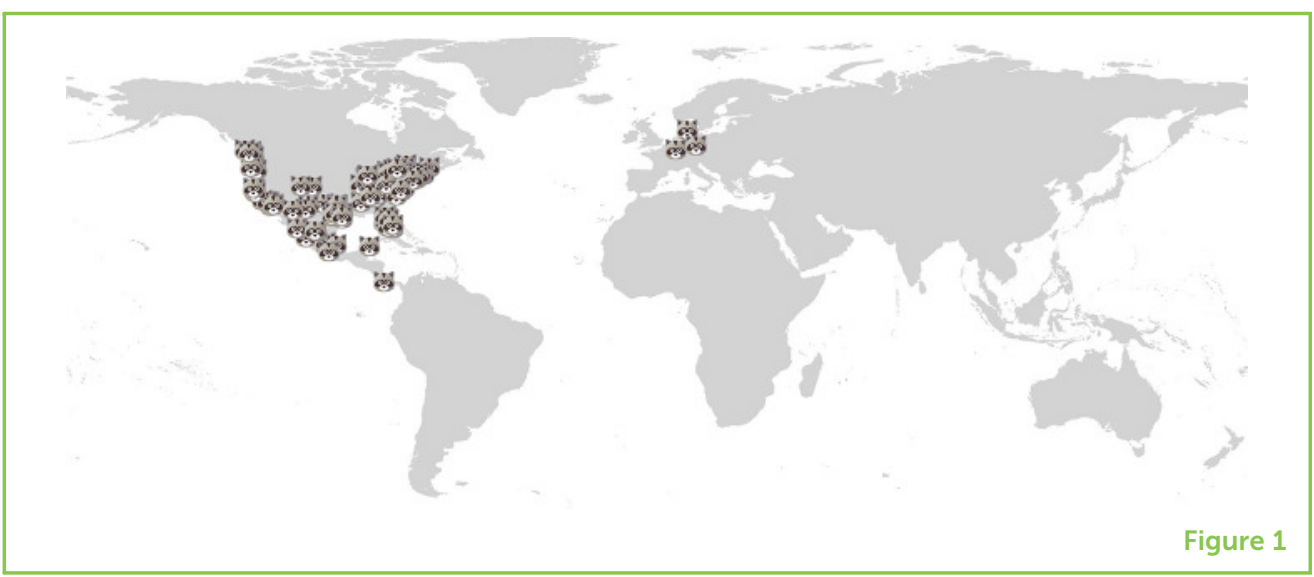

values between 0 and 1 for each place, representing the probability of finding a raccoon there, and it provided us with a map (Figure 2). Regions with similar characteristics to the ones where raccoons had previously been found had high probability values, meaning raccoons could live in these areas.

You can see that the computer helped us find where we should go first if we want to find raccoons! If a place has a high value, we should go there first because the chances are very high that we will find raccoons there. Sometimes the computer says that we should go to places where we already know there are not any raccoons, such as locations in the southern hemisphere. Therefore, it is important that humans validate a computer's answers and only use them to guide our searches. We can thus help computers to avoid making such mistakes. Because the world is changing, raccoons will constantly be moving and adapting to new places, making computers' jobs even more valuable. Computers can even help us to predict where we might be able to find raccoons in the near future.

Computers can be used to look for any living creature-not just raccoons-and they can even be used to look for non-living things. For example, if we want to look for another kind of animal that behaves just like raccoons, our maps could show us where opossums live! Opossums belong to another species, but like raccoons, they have an omnivorous diet and nocturnal habits, and the cubs stay with their mothers during their first months of life.

\section{WHEN ANIMALS MOVE TO NEW PLACES}

But why cannot we find raccoons and opossums in all the locations that are suitable for them, if they can easily adapt to many kinds of places? One reason is their ability to disperse, which often requires being able to overcome nature's obstacles such as rivers, mountains or even harsh environments. Even if a racoon can overcome these obstacles and settle in a new location, it should be able to reproduce 
Figure 2

This map shows the computer's guess as to where raccoons could live, based on the characteristics of each environment. Notice that the computer does not know that raccoons do not live in the southern hemisphere, so it is important for humans to validate the results generated by computer algorithms!

\section{INVASIVE SPECIES}

Species introduced to a new environment that have harmful impacts on that environment.

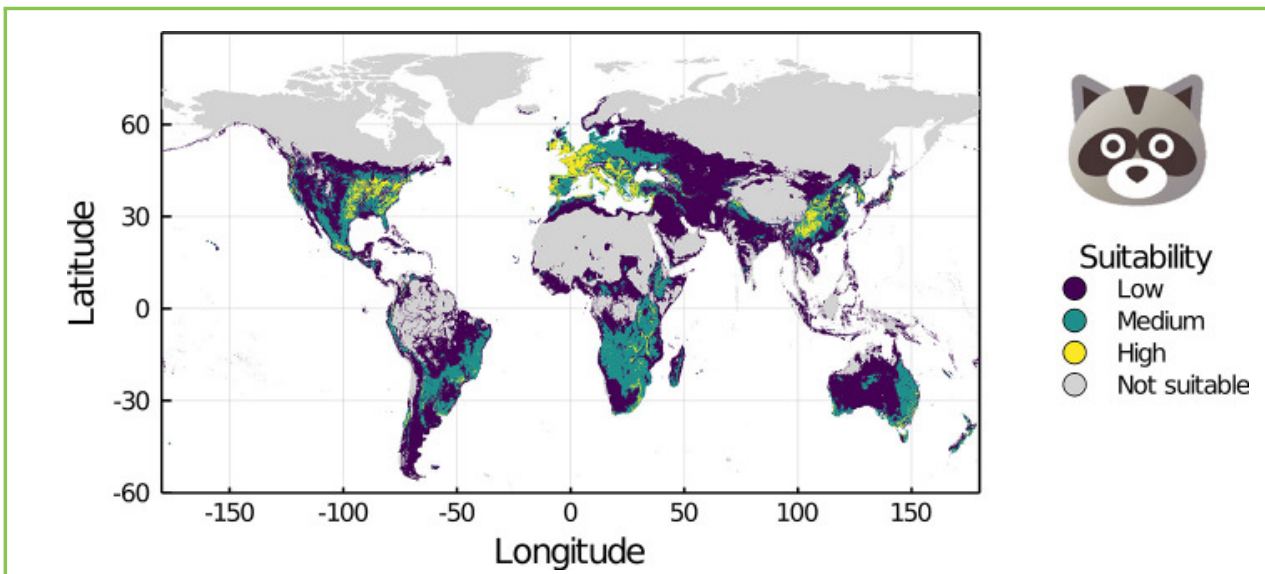

Figure 2

and start new populations, but that might be difficult if not many racoons are there as well [3]. Animal species move to new homes for many reasons, maybe because the environment in their old home has changed or because humans change conditions in new places, making it easier for the animals to move there [3]. On the other hand, it is not because a place is great to live that we want to move: these places are not good enough if our friends and family are not there. For our animals and plants this means not finding other animals and plants they need to interact with, like when there are no pollinators for a fruit tree.

Sometimes, when plants or animals move to a new place that contains different types of species than they were used to in their original home, those new plants or animals can become a huge problem. When this happens, we call them invasive species. Invasive species can reproduce too much, eat too many of the native species, or cause the native species to reproduce too much. The kind of maps we create using computers help us stay aware of the locations where species could move and possibly become invasive [1]. We can then try to prevent invasive species from establishing themselves in these locations, if needed, or even cautiously move species to new locations if they are about to go extinct in their old homes.

\section{YOUR TURN!}

Now it is your turn to be a scientist! Using Figure 2, find where you live and see if the map says it would be easy to find raccoons living there. Help us validate our computer's predictions by verifying if indeed there are raccoons where we think there might be! Does the map say there might be raccoons living in your area, yet you know for sure there are no raccoons there?

With the help of readers like you, we can work to improve our computer algorithms to better predict where various species of 
animals and plants might be found. In order to do that, scientists need a lot of data, especially the ones that tell where species are already found. A good way to collect these data is through community science platforms, such as eBird and iNaturalist, where everyone can add records of observed species. Then scientists can use this data and their computers to understand how we can protect species-for example, by making maps like the ones we did here that inform where our species can thrive and where they can go extinct. This means that everyone-including you!-can help us protect nature just by observing species and sharing this information online.

\section{ACKNOWLEDGMENTS}

The authors thank all members from the Poisot Lab for contributing in the initial brainstorm for conceiving the paper. We wrote this article on land located within the traditional unceded territory of the Saint Lawrence Iroquoian, Anishinabewaki, Mohawk, Huron-Wendat, and Omàmiwininiwak nations.

\section{REFERENCES}

1. Louppe, V., Leroy, B., Herrel, A., and Veron, G. 2019. Current and future climatic regions favourable for a globally introduced wild carnivore, the raccoon Procyon lotor. Sci. Rep. 9:9174. doi: 10.1038/s41598-019-45713-y

2. Gomes, V. H. F., IJff, S. D., Raes, N., Amaral, I. L., Salomão, R. P., de Souza Coelho, L., et al. 2018. Species distribution modelling: contrasting presence-only models with plot abundance data. Sci. Rep. 8:1003. doi: 10.1038/s41598-017-18927-1

3. Prange, S., Gehrt, S. D., and Wiggers, E. P. 2004. Influences of anthropogenic resources on raccoon (Procyon lotor) movements and spatial distribution. J. Mamm. 85:483-90. doi: 10.1644/1383946

SUBMITTED: 15 August 2020; ACCEPTED: 21 May 2021; PUBLISHED ONLINE: 24 June 2021.

EDITED BY: Didone Frigerio, University of Vienna, Austria

CITATION: Higino GT, Forero N, Banville F, Dansereau G and Poisot T (2021) Computers Can Help us Find Raccoons and Other Living Creatures. Front. Young Minds 9:595275. doi: 10.3389/frym.2021.595275

CONFLICT OF INTEREST: The authors declare that the research was conducted in the absence of any commercial or financial relationships that could be construed as a potential conflict of interest.

COPYRIGHT (c) 2021 Higino, Forero, Banville, Dansereau and Poisot. This is an open-access article distributed under the terms of the Creative Commons Attribution License (CC BY). The use, distribution or reproduction in other forums is permitted, provided the original author(s) and the copyright owner(s) are credited 

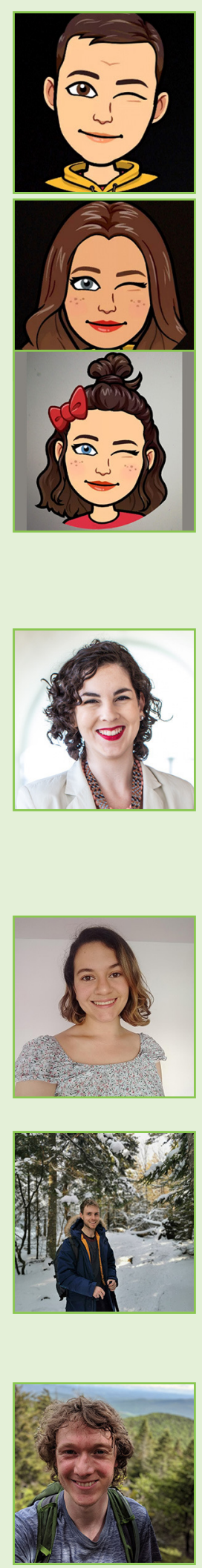

and that the original publication in this journal is cited, in accordance with accepted academic practice. No use, distribution or reproduction is permitted which does not comply with these terms.

\section{YOUNG REVIEWERS}

\section{DARIO, AGE: 14}

My name is Dario. I live in a small village in Austria. It is full of nature so in my freetime I like to go out with my dogs or climb trees. My parents are both biologist so I got into biology pretty early.

\section{LEONIE, AGE: 13}

I am in 8th grade of a middle school in Austria. My hobbies are doing gymnastics, drawing, and reading. I also like to meet my friends.

\section{VALERIE, AGE: 13}

I am in 8th grade of a middle school in Austria. My hobbies are horsebackriding, skating, and dancing. I have got a very old cat and we are getting a dog soon. I also like meeting my friends and listening to some music.

\section{AUTHORS}

\section{GRACIELLE TEIXEIRA HIGINO}

Gracielle is an ecologist trying to understand how the world works by making fake species in a fake environment, but also by translating parts of nature into numbers. Her dreams are to understand why species are distributed the way we see them today and to be fluent in French. She loves reading, spending time in parks, and playing with the videogame she assembled herself using a RaspberryPi. *graciellehigino@gmail.com

\section{NORMA FORERO}

Norma is a Ph.D. student in Biology at Universite de Montreal. Her research focuses on understanding the dynamic of diseases that affect people and animals (domestic and wildlife), using computers to analyze data about the place where they live and how interact.

\section{FRANCIS BANVILLE}

Francis is a Ph.D. candidate in biology at the University of Montreal. His research focuses on the many interactions between species all over the world. More precisely, he uses mathematical and computational tools to predict how species interact in a given environment. In his free time he enjoys playing board games and running in the snowy streets of Montreal.

\section{GABRIEL DANSEREAU}

Gabriel is an M.Sc. student in biology at the University of Montreal. His research interests are species distributions (where species are found) and biodiversity hotspots (exceptional places where you can find either many species, few species, rare species, or unusual species combinations). 


\section{TIMOTHÉE POISOT}

Timothée Poisot is a computational ecologist interested in solving ecological questions using tools from data science, applied mathematics, and machine learning; his research focuses on understanding and predicting interactions between species. 